\title{
Age, anti-müllerian hormone, antral follicles count to predict amenorrhea or oligomenorrhea after chemotherapy with cyclophosphamide
}

\author{
Ângela Marcon D'Avila', Vanderlei Biolchi ${ }^{2}$, Edison Capp ${ }^{1,2,3,4,6^{*}}$ (1) and Helena von Eye Corleta ${ }^{1,3,5}$
}

\begin{abstract}
Background: A cohort study was performed to identify ovarian reserve markers (ORM) that predicts amenorrhea or oligomenorrhea 6 months after cyclophosphamide CTX in women with breast cancer.

Methods: 52 eumenorrheic patients with breast cancer were enrolled. FSH, anti-Müllerian hormone (AMH), antral follicles count (AFC) were measured before and 6 months after CTX. A logistic regression for independent samples and determination of the ROC curve were performed.

Results: The age of 32 years presented $96 \%$ of sensitivity and $39 \%$ of specificity to predict amenorrhea or oligomenorrhea with ROC area under the curve (AUC) of 0.77 . ovarian reserve marker (ORM) with power to predict amenorrhea or oligomenorrhea in women after CTX were AMH $<3.32 \mathrm{ng} / \mathrm{mL}$ (sensitivity of $85 \%$, specificity of $75 \%$ and AUC 0.87), AFC $<13$ follicles (sensitivity $81 \%$, specificity $62 \%$, AUC 0.81). AMH cutoff to predict amenorrhea was $1.87 \mathrm{ng} / \mathrm{mL}$ (sensitivity $82 \%$, specificity $83 \%$, AUC 0.84) and AFC cutoff was 9 follicles (sensitivity $71 \%$, specificity $78 \%$, AUC 0.73).

Conclusions: $\geq 32$-years-old women, $\mathrm{AMH}<3.32 \mathrm{ng} / \mathrm{mL}$ and AFC $<13$ follicles determined significantly higher risk of amenorrhea or oligomenorrhea after CTX with cyclophosphamide. The ORM age ( $\geq 32$ years) analyzed together with AMH or AFC increases sensitivity and specificity in predicting amenorrhea or oligomenorrhea.
\end{abstract}

Keywords: Anti-Müllerian hormone, Antral follicles count, Ovarian reserve, Amenorrhea related chemotherapy, Anovulation related chemotherapy

\section{Background}

Currently, around $5 \%$ of the malignant neoplasias affect people younger than 35 years old [1]. In the United States, approximately 50,000 new cases of malignancy are diagnosed per year in young people [2]. Breast cancer is the second most frequent malignancy, affecting around 11,000 women per year [3]. The prognosis of malignancy improved because of early diagnosis and CTX treatment, which, despite their effectiveness against the disease, can have

\footnotetext{
* Correspondence: edcapp@ufrgs.br

'Graduate Program in Medicine: Medical Sciences, Universidade Federal do Rio Grande do Sul School of Medicine, Bento Gonçalves, RS, Brazil

${ }^{2}$ Graduate Program in Biological Sciences: Physiology, Instituto de Ciências Básicas da Saúde, Universidade Federal do Rio Grande do Sul, Lajeado, RS, Brazil

Full list of author information is available at the end of the article
}

damaging effect on the gonadal function, compromising reproductive future $[2,4]$.

Among chemotherapic agents, the alkylating are those with the higher gonadotoxic potential. The impact of chemotherapy on the reproductive future of the patients exposed to CTX is determined by their age, type and dose of chemotherapic agents, length of treatment and chemotherapic agents association [5-7]. However, the literature is poor about the importance of assessing ovarian reserve (OVR) before undergoing CTX treatment to predict the reproductive prognosis after the cure of the disease $[4,8]$.

OVR refers to quantity and, to some authors, quality of follicles present in ovaries at a given time. It is the measure of oocyte production and consequently reproductive 
potential $[9,10]$. Its evaluation is through serum analysis of FSH, estradiol, inhibin and anti-Müllerian hormone (AMH) and through ultrasonographic counting of antral follicles (AFC) [11]. AFC refers to the number of follicles visible in ovaries during ultrasound scan in the first days of the menstrual cycle. There is controversy in the literature about the size of follicles that must be counted, 2 to $5 \mathrm{~mm}$ or 2 to $10 \mathrm{~mm}[1,9]$. AMH is a dimeric glycoprotein that determines the anatomy of the female internal genitalia and works in the development of primordial and growing follicles. It has been hypothesized as the most reliable ovarian reserve marker (ORM), because its levels do not vary during the menstrual cycle and it is not detectable in menopause $[1,12]$.

As fertility preservation may be a priority for young women with cancer, we analyzed which ORM can be used as predictors of anovulation (oligomenorrhea or amenorrhea) 6 months after CTX with cyclophosphamide in women with breast cancer.

\section{Results and discussion}

The mean age of patients was $35.3 \pm 3.8$ years (range 2740 years) and the age distribution is presented in Table 1. The main histological type of breast cancer was invasive ductal carcinoma (98\%). Forty percent of patients underwent breast-conserving surgery prior to or followed by CTX treatments and $75 \%$ of patients underwent adjuvant radiotherapy. The follow-up mean time was $14 \pm 3$ months since the first assessment. Five patients quit the follow-up study. Three for recurrence of the disease, making it impossible to attend the assessment appointment, one gave

Table 1 Clinical characteristics of patients

\begin{tabular}{|c|c|c|}
\hline & $\mathrm{n}$ (total = 52) & $\%$ \\
\hline \multicolumn{3}{|l|}{ Age (years) } \\
\hline$<32$ & 8 & 15 \\
\hline$\geq 32$ & 44 & 85 \\
\hline $32-35$ & 17 & 33 \\
\hline $36-38$ & 11 & 21 \\
\hline $39-40$ & 16 & 31 \\
\hline \multicolumn{3}{|l|}{ BMI $\left(\mathrm{kg} / \mathrm{m}^{2}\right)^{*}$} \\
\hline Eumenorrheic & $26.16 \pm 16.0$ & \\
\hline Anovulatory & $24.4 \pm 3.3$ & \\
\hline \multicolumn{3}{|l|}{ Tumor type } \\
\hline Ductal invasive & 51 & 98 \\
\hline Paget Disease & 1 & 2 \\
\hline \multicolumn{3}{|l|}{ Chemotherapy } \\
\hline Neoadjuvant & 21 & 40 \\
\hline Adjuvant & 31 & 60 \\
\hline Radiation therapy & 41 & 79 \\
\hline
\end{tabular}

${ }^{*} P=0.18$ up the treatment and another died. Mean cycles number for ciclofosfamide was 4.5 per patient and 1,4 for paclitaxel (34 patients used paclitaxel associated to ciclofosfamide). There was no difference in the number of cycles between patients with regular cycles and those with amenorrhea and oligomenorrhea.

Patients with 32 years of age or younger had levels of $\mathrm{AMH}$ similar to those of patients older than 32 years old (5.41 [0.20-24.55]) and 2.32 [0.0-13.66], respectively) and AFC were significantly higher than patients older than 32-years (respectively 14.0 [8.0-20.0] and 10.0 [6.0$18.0], p=0.061$ and $p=0.023)$. FSH was not different in this analysis.

Thirty-nine percent of patients were amenorrheic 6 months after CTX, $21 \%$ were oligomenorrheic and $40 \%$ eumenorrheic. The baseline ORM were related to menstrual outcome after CTX, showing that the amenorrheic women and women with regular menstrual cycles are statistically different with regard to age, $\mathrm{AMH}$ and AFC, with $p=0.006 ;<0.001 ; 0.003$, respectively. Comparing oligomenorrheic patients (irregular menstrual cycles) versus amenorrheic and oligomenorrheic versus eumenorrheic patients no differences were found in age, AMH or AFC (Table 2).

Aiming to define the risk predictors for significant OVR loss of after CTX, the researchers decided to create a group with menstrual irregularity (oligomenorrheic and amenorrheic patients) in order to compare it with the group that remain eumenorrheic after CTX. The mean age of women with oligomenorrhea or amenorrhea six months after CTX was $36.5 \pm 3.8$ years, while women with regular cycles had a mean age of $32.9 \pm 3.5$ years $(p=0.02)$. The AFC, independently of age, was statistically significant for risk prediction for oligomenorrhea or amenorrhea $(p=0.001$ and confidence interval $[\mathrm{CI}]$ 0.548-0.931). AMH also showed to be a good predictor for the decline of reproductive function, with $p<0.001$ and CI 0.541-0.941 (Table 3).

Baseline estradiol levels, smoking habits and body mass index were not different between the oligomenorrheic and amenorrheic group and the regular cycling group 6 months after CTX.

Table 4 shows ORM analyzed through logistic regression. The multiple regression used to analyze many variables together was not possible because of the multicollinearity of age, $\mathrm{AMH}$ and $\mathrm{AFC}$, therefore the

Table 2 ORM before CTX and menstrual outcome 6 months after CTX

\begin{tabular}{llll}
\hline & $\begin{array}{l}\text { Eumenorrhea } \\
(19 \text { patients })\end{array}$ & $\begin{array}{l}\text { Oligomenorrhea } \\
(10 \text { patients })\end{array}$ & $\begin{array}{l}\text { Amenorrhea } \\
(18 \text { patients })\end{array}$ \\
\hline Age (years) & $32.9 \pm 3.5$ & $35.7 \pm 3$ & $36.9 \pm 3.4^{*}$ \\
AMH (ng/mL) & $5.34(2.71-8.15)$ & $3.21(1.55-4.74)$ & $0.92(0.24-1.66)^{* *}$ \\
AFC (follicles) & $13.5(11-16)$ & $10(8-12)$ & $9(7.5-12)^{* * *}$ \\
\hline Eumenorrhea X Amenorrhea ${ }^{*} p=0.006 ;{ }^{* *} p<0.001 ;{ }^{* * *} p=0.003$
\end{tabular}


Table 3 Baseline ORM related to menstrual outcome 6 months after CTX group of anovulatory patients (oligomenorrheic and amenorreic) and group of ovulatory patients (eumenorrheic)

\begin{tabular}{lll}
\hline & $\begin{array}{l}\text { Eumenorrhea } \\
(n=19)\end{array}$ & $\begin{array}{l}\text { Oligomenorrhea + Amenorrhea } \\
(n=28)\end{array}$ \\
\hline Age (years) & $32.9 \pm 3.5$ & $36.5 \pm 3.8^{*}$ \\
AMH (ng/mL) & $5.34(2.71-8.15)$ & $1.31(0.72-2.89)^{* *}$ \\
AFC (follicles) & $13.5(11-16)$ & $9(7.75-12)^{* *}$ \\
\hline
\end{tabular}

Oligomenorrhea + Amenorrhea X Eumenorrhea (Regular cycles): ${ }^{*} p=0.02 ;{ }^{* *} p<0.001$

analysis was independently performed for each variable controlled by age. The age of 32 showed sensitivity $96 \%$ and specificity $39 \%$ to predict cycle irregularity. The odds ratio (OR) for oligomenorrhea or amenorrhea in patients $\geq$ 32-years-old was 15.9 with CI 1-145, $p=0.03$ (Table 4). The Positive Predictive Value (PPV) of $\geq 32$ years for anovulation was $70 \%$ and the Negative Predictive Value (NPV) was $87 \%$. Figure 1 represents the ROC curve that defines the most accurate age to predict oligomenorrhea or amenorrhea, 32 years, with AUC 0.77 (Fig. 1). Analyzing exclusively amenorrheic women 6 months after CTX, the age of 35 years or more predicted amenorrhea with sensitivity $76 \%$, specificity $66 \%$, CI $0.53-0.85$ and AUC of 0.69 .

FSH was not a predictor of oligomenorrhea and amenorrhea after CTX. However, women with $\geq 32$-years-old and $\mathrm{FSH} \geq 6.66 \mathrm{UI} / \mathrm{mL}$ had significantly higher oligo or amenorrheic cycles than women with FSH lower than this cut off, with OR 6.36 (CI 1.11-36.41), $p=0.021$ with sensitivity $60 \%$ and specificity $82 \%$ (Table 4 ). The PPV of FSH 6.66 IU in women older than 32 years was $73 \%$, while the NPV was $55 \%$.

The cut off for AFC was $<13$ follicles to predict oligomenorrhea or amenorrhea. Patients with $<13$ follicles presented higher risk of oligomenorrhea or amenorrhea 6 months after CTX, with sensitivity $81 \%$, specificity $62 \%$ and AUC 0.81 (Fig. 1b). The OR was 4.43 (CI 0.943-20.8, $p=0.059$ ) (Table 4). The PPV of AFC of $<13$ follicles for oligomenorrhea or amenorrhea was $78 \%$, while the NPV was $67 \%$. Although there was no statistical significance, $33 \%$ of the patients with AFC $\geq 13$ developed oligomenorrhea or amenorrhea, while $78 \%$ with AFC $<13$ developed the same outcome.

Values of $\mathrm{AMH}$ under $3.32 \mathrm{ng} / \mathrm{mL}$ presented sensitivity $85 \%$ and specificity $75 \%$ to occurrence of oligomenorrhea or amenorrhea. The ROC AUC for $3.32 \mathrm{ng} / \mathrm{mL}$ was 0.86
(Fig. 1b). Only $20 \%$ of the patients with AMH > 3.32 ng/ $\mathrm{mL}$ presented oligomenorrhea or amenorrhea, while $80 \%$ of the women with $\mathrm{AMH}$ under this cut off resulted in the same outcome. OR for oligomenorrhea or amenorrhea in women with AMH levels < $3.32 \mathrm{ng} / \mathrm{mL}$ was 10.3 (CI 2.14 50.37, $p=0.04$ ) (Table 4). The PPV of AMH of $3.32 \mathrm{ng} / \mathrm{mL}$ oligomenorrhea or amenorrhea was $79 \%$, while the NPV was $75 \%$.

Analyzing exclusively amenorrheic women 6 months after CTX, the cut off to predict amenorrhea was $1.87 \mathrm{ng} /$ $\mathrm{mL}$ for $\mathrm{AMH}$, sensitivity of $82 \%$, specificity of $83 \%$, AUC of 0.84 ) and 9 follicles for AFC, sensitivity $71 \%$, specificity $78 \%$ and AUC 0.73 .

Table 5 shows the analysis in series and in parallel of the AMH $(<3.32 \mathrm{ng} / \mathrm{mL})$ and AFC $(<13)$ with the clinical ORM age $\geq 32$ years aimed to increase sensitivity in predicting oligomenorrhea or amenorrhea when tests were used in parallel and to increase specifity when used in series. The specifity for oligomenorrhea or amenorrhea when age ( $\geq 32$ years) was analyzed in series with $\mathrm{AMH}$ $(<3.32 \mathrm{ng} / \mathrm{mL})$ was $80 \%$ and with AFC $(<13)$ was $78 \%$. The analysis of ORM was not influenced by the number of cycles (4 or 6), dose of CTX calculated according to body mass index, or by radiotherapy association. The cyclophosphamide dosage was $600 \mathrm{mg} / \mathrm{m} 2,43$ patients did 4 cycles and 6 patients did 6 cycles. The menstrual pattern and the ovarian reserve markers were not different between the groups. The AMH was $0.57 \pm 2.29$ and $0.16 \pm 1.01$ and AFC was $5.2 \pm 3.1$ and $6.0 \pm 3.3$ in the groups of 4 and 6 cycles respectively. The Pearson correlation between cyclophosphamide dose and $\mathrm{AMH}$, FSH and AFC 6 months after CTX was, respectively, 0.24 with $p=0.944,-0.442$ with $p=0.174$ and 0.21 with $p=0.342$.

This cohort study evaluated the sensitivity and specificity of the ORM (age, FSH, AMH, AFC) and correlate them with the occurrence of oligomenorrhea or amenorrhea in young women with breast cancer exposed to CTX with cyclophosphamide (there is one study in women younger than 40 years old) [13]. The occurrence of amenorrhea in these patients has been reported as up to $70 \%$, varying with the age of the woman [13]. In our study, the incidence of oligomenorrhea or amenorrhea, associated with decreased fertility, 6 months after CTX was $60 \%$ and the incidence of amenorrhea (ovarian failure or premature menopause) in the same period was $39 \%$.

Table 4 ORM cut off in predicting amenorrhea or oligomenorrhea 6 months after CTX with cyclophosphamide

\begin{tabular}{|c|c|c|c|c|c|c|}
\hline & Cut Off & $p$ & OR & $\mathrm{Cl}$ & Sensitivity & Specificity \\
\hline Age & $\geq 32$ anos & 0.03 & 15.9 & $1-145$ & $96 \%$ & $39 \%$ \\
\hline $\mathrm{AMH}$ & $<3.32 \mathrm{ng} / \mathrm{mL}$ & 0.04 & 10.3 & $2.14-50.37$ & $85 \%$ & $75 \%$ \\
\hline AFC & $<13$ folículos & 0.059 & 4.43 & $0.943-20.8$ & $81 \%$ & $62 \%$ \\
\hline FSH ( $\geq 32$ years) & $\geq 6.66 \mathrm{UI} / \mathrm{mL}$ & 0.021 & 6.36 & $1.11-36.41$ & $60 \%$ & $82 \%$ \\
\hline
\end{tabular}




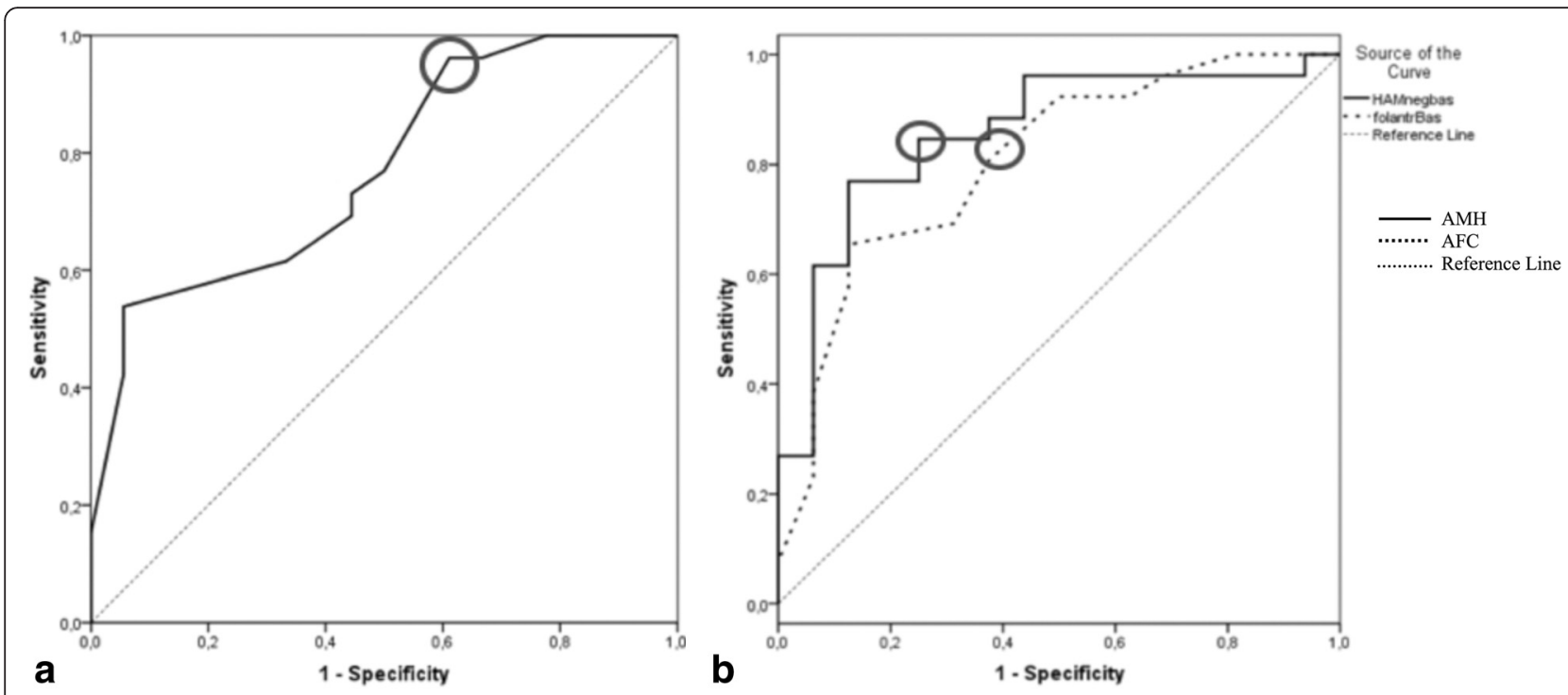

Fig. 1 a ROC curve for age in predicting amenorrhea or oligomenorrhea 6 months after CTX. AUC $=0.77$; $c$ ircle $=$ age $>32$. b AMH and $A F C$ ROC curve for amenorrhea or oligomenorrhea 6 months after CTX. Circles on the curves indicate the cut off with better sensitivity and specificity in predicting cycle irregularity. $\mathrm{AUC}(\mathrm{AMH})=0.86$. $\mathrm{AUC}(\mathrm{AFC})=0.81$

Age and CTX treatment are among the main predictor factors for occurrence of menopause in eumenorrheic women with breast cancer [14]. Levels of AMH before gonadotoxic CTX also seem to be a predictor [15]. Anderson et al. followed women with breast cancer for 5 years and demonstrated that AMH levels lower than $1.9 \mathrm{ng} / \mathrm{mL}$ are predictor of ovarian failure [16]. Dillon et al., recently described in 33 women treated with alkilating agents that pretreatment AMH level was associated with the rate of recovery of $\mathrm{AMH}$ after treatment. $\mathrm{AMH}$ level $>2 \mathrm{ng} / \mathrm{mL}$ recovered at a rate of $11.9 \%$ per month after chemotherapy, whereas participants with pretreatment AMH levels $\leq 2 \mathrm{ng} / \mathrm{mL}$ recovered at a rate of $2.6 \%$ per month after therapy [14]. According to Van Roiij et al., patients with irregular cycles already show significant decline in their reproductive function [12]. Singh et al. reported the importance of predicting the decline of OVR in patients with breast cancer, even when there is no amenorrhea [17]. Thus, the outcome in our study was considered oligomenorrhea or amenorrhea, comparing it to regular cycles (ovulatory), women 6 months after CTX. It was the author's decision to assess together the oligomenorrhea and amenorrhea group since it has

Table 5 AMH cut off ( $3.32 \mathrm{ng} / \mathrm{mL}$ ) analyzed concomitantly with other ORM in parallel and in series, the prediction of amenorrhea or oligomenorrhea

\begin{tabular}{llllll}
\hline Age $\geq 32$ years & \multicolumn{2}{l}{ Parallel test } & & \multicolumn{2}{l}{ Series test } \\
\cline { 2 - 3 } \cline { 6 - 6 } \cline { 6 - 6 } & Sensivity & Specificity & & Sensivity & Specificity \\
\hline AMH $\leq 3,32$ & $99,4 \%$ & $26 \%$ & & $81 \%$ & $80 \%$ \\
AFC $<13$ follicles & $99 \%$ & $24 \%$ & & $78 \%$ & $78 \%$ \\
\hline
\end{tabular}

been demonstrated that both represent a sign of lower fertility [18], related to anovulation. In the literature there are no studies that consider oligomenorrhea or amenorrhea as an outcome of CTX gonadotoxicity.

Petrek et al. found a greater incidence of amenorrhea after CTX in women older than 40 years of age [19]. Gracia et al., in a transversal study analyzing the ovarian reserve in 61 cancers survivors, compared with 67 healthy, similarly aged unexposed subjects; and 69 regularly menstruating women of late reproductive age, concluded ORM (FSH, AMH, and AFC) differed between exposed vs. unexposed subjects; and are similar with women of late reproductive age [4]. Tiong et al. described amenorrhea to be reversible 15 months after CTX [20]. Our study, however, enrolled 52 women under 40 years old and was able to define more precisely which women, younger than 40 years old, will have greater impairment in their reproductive capacity. Age that determines a higher incidence of amenorrhea was 35. However, to define at which age women will loss of the reproductive function, even with irregular cycle presence, we chose an age cut off with a higher sensitivity, without loss of specificity, in predicting risk of anovulation, i.e., 32 years. The age of $\geq 32$ years shows sensitivity near $100 \%$ for oligomenorrhea or amenorrhea and ORM (AMH and AFC) in this group were significantly lower than in younger women. Therefore, for patients without offspring, 32 years seems to be the age to alert doctors and patients to preserve fertility prior to CTX.

FSH was not a good ORM, as demonstrated by other authors. Significant FSH changes occur only with amenorrhea being a marker of ovarian failure and not of 
decline in OVR [7, 21]. However, FSH greater than or equal to $6.66 \mathrm{IU} / \mathrm{mL}$ in women over 32 years of age seems to carry a higher risk of cycle irregularity after CTX. Similar analysis was not found in the literature.

With respect to the AFC, it was demonstrated that patients witr less than 13 follicles, independent of age, are more susceptible to oligomenorrhea or amenorrhea (OR 4.43, sensitivity of $81 \%$ and specificity of $62 \%$ and $p=0,059)$. We believe that no statistical significance for the AFC in the prediction of oligomenorrhea or amenorrhea in this group of patients is due to the calculation of the sample size, which aimed to find differences in the AMH levels. Anderson et al., in a similar study, did not describe the cut off in the number of antral follicles associated with amenorrhea. They reported that the AFC mean before CTX in women who maintained ovulatory cycles was 19 versus 8 in those who developed amenorrhea [16].

$\mathrm{AMH}$ values greater than or equal to $3.32 \mathrm{ng} / \mathrm{mL}$, regardless of the patient's age, are protective for the occurrence of oligomenorrhea or amenorrhea after CTX with cyclophosphamide, with sensitivity $85 \%$ and specificity $75 \%$. Even with a high confidence interval in this analysis, the OR was 10.3 meaning that patients with $\mathrm{AMH}$ $<3.32 \mathrm{ng} / \mathrm{mL}$ are 10 times more likely to develop oligomenorrhea or amenorrhea.

Previously, Anders et al. demonstrated that AMH values below $1.09 \mathrm{ng} / \mathrm{mL}$ increased the risk of amenorrhea after CTX in the evaluation of 44 patients with breast cancer and a mean age of 40 years [22]. Anderson et al. in 2011 conducted a similar study and found that value of $\mathrm{AMH}$ of $1.9 \mathrm{ng} / \mathrm{mL}$ with sensitivity of $54 \%$ and specificity of $92 \%$, ROC AUC 0.91 and OR 7.0 as a predictor of risk for amenorrhea during a 5-year follow-up study of 42 women exposed to CTX [16]. Our results were similar to the occurrence of amenorrhea, finding $\mathrm{AMH}$ values below $1.87 \mathrm{ng} / \mathrm{mL}$ for this outcome. However, we prioritized the group of patients who would need counseling for fertility preservation, that is, those who would have their fertility compromised either by anovulation (amenorrhea and oligomenorrhea). Literature only shows studies that have evaluated OVR of patients who developed exclusive amenorrhea, patients with irreversible ovarian failure $[16,22]$. Aiming to increase the sensitivity in predicting decrease fertility (anovulation) and provide the greatest safety in medical indication for fertility preservation techniques, this study accomplished association between ORM to increase power in predicting oligo or amenorrhea. The ORM with great sensibility to predict amenorrhea and oligomenorrhea was age $\geq 32$ years, when this age was analyzed in parallel with $\mathrm{AMH}$ or AFC the sensibility reaches $99 \%$, and in series the specific was around $80 \%$.

\section{Conclusions}

Thirty-two years old or older women, serum $\mathrm{AMH}<$ $3.32 \mathrm{ng} / \mathrm{mL}$ or AFC $<13$ offer a higher risk of amenorrhea or oligomenorrhea after CTX with cyclophosphamide. The ORM age ( $\geq 32$ years) analyzed in series with AMH or AFC decrease the sensitivity in order to increases the specificity, making the result clinically useful with sensitivity and specificity around $80 \%$ to amenorrhea or oligomenorrhea after CTX. Parallel analysis offered a higher sensitivity but lower specificity, as false-positives were more common. Serial analysis demonstrated lower sensitivity than the parallel analysis, resulting in a better performance when clinically employed; however, the specificity was higher. Serial analysis of age and AMH or AFC was demonstrated to be better than analysis of age separately. These parameters should be considered during pretreatment fertility preservation counseling.

\section{Methods}

A cohort study was conducted. The study followed 52 eumenorrheic women younger than 40 years of age with breast cancer requiring CTX containing cyclophosphamide, who had not undergone previous CTX treatment. Patients were selected from six hospitals in Porto Alegre, Rio Grande do Sul, Brazil. The study protocol was approved by the corresponding Research Ethics Committees (HCPA \#07-061) and was conducted in accordance with Brazilian guidelines and standards for human subject research (National Research Council Resolution 196/96).

Sample size was calculated based on the study by van Rooij [12]. The minimum number of 44 patients was estimated to find a difference of $1.4 \mathrm{ng} / \mathrm{mL}$ in $\mathrm{AMH}$ values between baseline and 6 months after completion of CTX with a significance level of 0.05 and a power of $90 \%$.

Patients were assessed through interview, blood sampling and ultrasound scan before and 6 months after CTX. The blood samples were centrifuged at $3500 \mathrm{rpm}$ for $15 \mathrm{~min}$ and the serum was stored at $-80{ }^{\circ} \mathrm{C}$. Measurement of $\mathrm{FSH}$ and estradiol through chemiluminescence was performed using the ADVIA Centaur ${ }^{\circledR} \mathrm{XP}$ Immunoassay System (Siemens ${ }^{\oplus}$ ) (samples were collected at any time of menstrual cycle in order to avoid delay of chemotherapy begin). FSH and estradiol were measured on the day the patient performed transvaginal ultrasound, together with the other exams. It was not possible to wait for the best moment to collect this exams, since it could delay the onset of chemotherapy. AMH was measured through ELISA (Beckman Coulter, Genese Imunotech $^{\oplus}$, France), as described in the literature [23].

Patients were referred and the same researcher performed ultrasound scans in all patients with Siemens Sonoline Adara, an ultrasound device with vaginal probe of $5 \mathrm{MHz}$, any day within a menstrual cycle because of 
the urgency to begin CTX. All Follicles with a mean diameter between 2 and $10 \mathrm{~mm}$ were considered for AFC [24].

The analysis was performed with Statistical Package for Social Sciences (SPSS) 18. Results are presented as median and interquartile range (25-75\%) because the data of this study do not show Gaussian normal distribution. The data were tested with the Mann-Whitney test and the multiple comparisons were corrected through Bonferroni. The categorical variables were analyzed through Pearson ChiSquare test. A logistic regression for independent samples and determination of the ROC curve were performed. The significance level was considered $p<0.05$.

\section{Consent}

Written informed consent was obtained from the patiens for the publication of this report and accompanying images.

\section{Competing interests}

The authors declare that they have no competing interests.

\section{Authors' contributions}

AMD'A participated in the design of the study, recruited the patients, carried out the examination and ultrasound scans, and drafted the manuscript. VB participated in the design of the study and performed the statistical analysis. EC participated in the design of the study and performed the statistical analysis and drafted the manuscript. HvEC conceived of the study, and participated in its design and coordination and helped to draft the manuscript. All authors read and approved the final manuscript.

\section{Acknowledgments}

This project was funded by the Fundo de Incentivo à Pesquisa (FIPE), Grupo de Pesquisa e Pós-Graduação (GPPG \#07061), Hospital de Clínicas de Porto Alegre. Edison Capp is a scholarship recipient from Conselho Nacional de Desenvolvimento Científico e Tecnológico - CNPq.

\section{Author details}

${ }^{1}$ Graduate Program in Medicine: Medical Sciences, Universidade Federal do Rio Grande do Sul School of Medicine, Bento Gonçalves, RS, Brazil. ${ }^{2}$ Graduate Program in Biological Sciences: Physiology, Instituto de Ciências Básicas da Saúde, Universidade Federal do Rio Grande do Sul, Lajeado, RS, Brazil. ${ }^{3}$ Department of Obstetrics and Gynecology, Hospital de Clínicas de Porto Alegre, Sul School of Medicine, Universidade Federal do Rio Grande do Sul, Porto Alegre, RS, Brazil. ${ }^{4}$ Department of Gynecological Endocrinology and Reproductive Medicine, University Hospital Heidelberg, Heidelberg, Germany. ${ }^{5}$ GENERAR, Porto Alegre, RS, Brazil. ${ }^{6}$ Serviço de Ginecologia e Obstetrícia Hospital de Clínicas de Porto Alegre Rua Ramiro Barcelos, 2350/11 ${ }^{\circ}$ andar, Porto Alegre CEP 90035-903, RS, Brazil.

Received: 22 October 2015 Accepted: 9 December 2015

Published online: 14 December 2015

\section{References}

1. Rosen MP, Johnstone E, McCulloch CE, Schuh-Huerta SM, Sternfeld B, Reijo-Pera RA, et al. A characterization of the relationship of ovarian reserve markers with age. Fertil Steril. 2012;97(1):238-43.

2. Knopman JM, Papadopoulos EB, Grifo JA, Fino ME, Noyes N. Surviving childhood and reproductive-age malignancy: effects on fertility and future parenthood. Lancet Oncol. 2010;11(5):490-8.

3. DeSantis C, Siegel R, Bandi P, Jemal A. Breast cancer statistics, 2011. CA Cancer J Clin. 2011;61(6):409-18.

4. Gracia CR, Sammel MD, Freeman E, Prewitt M, Carlson C, Ray A, et al. Impact of cancer therapies on ovarian reserve. Fertil Steril. 2012;97(1):134-40. e131.

5. Stroud JS, Mutch D, Rader J, Powell M, Thaker PH, Grigsby PW. Effects of cancer treatment on ovarian function. Fertil Steril. 2009;92(2):417-27.
6. Sonmezer $\mathrm{M}, \mathrm{Oktay} \mathrm{K}$. Fertility preservation in young women undergoing breast cancer therapy. Oncologist. 2006;11(5):422-34.

7. Anderson RA, Wallace WH. Antimullerian hormone, the assessment of the ovarian reserve, and the reproductive outcome of the young patient with cancer. Fertil Steril. 2013;99(6):1469-75.

8. Practice Committee of the American Society for Reproductive M. Testing and interpreting measures of ovarian reserve: a committee opinion. Fertil Steril. 2012;98(6):1407-15.

9. Broekmans FJ, Kwee J, Hendriks DJ, Mol BW, Lambalk CB. A systematic review of tests predicting ovarian reserve and IVF outcome. Hum Reprod Update. 2006;12(6):685-718.

10. Testing and interpreting measures of ovarian reserve: a committee opinion. Fertility and sterility. 2012; 98(6): 1407-1415

11. Bozza C, Puglisi F, Lambertini M, Osa EO, Manno M, Del Mastro L. Anti-Mullerian hormone: determination of ovarian reserve in early breast cancer patients. Endocr Relat Cancer. 2014;21(1):R51-65.

12. van Rooij IA, Tonkelaar I, Broekmans FJ, Looman CW, Scheffer GJ, de Jong $\mathrm{FH}$, et al. Anti-mullerian hormone is a promising predictor for the occurrence of the menopausal transition. Menopause. 2004;11(6 Pt 1):601-6.

13. Shapiro $\mathrm{CL}$, Recht $\mathrm{A}$. Side effects of adjuvant treatment of breast cancer N Engl J Med. 2001;344(26):1997-2008.

14. Dillon KE, Sammel MD, Prewitt M, Ginsberg JP, Walker D, Mersereau JE, et al Pretreatment antimullerian hormone levels determine rate of posttherapy ovarian reserve recovery: acute changes in ovarian reserve during and after chemotherapy. Fertil Steril. 2013;99(2):477-83.

15. Dunlop CE, Anderson RA. Uses of anti-Mullerian hormone (AMH) measurement before and after cancer treatment in women. Maturitas. 2015;80(3):245-50.

16. Anderson RA, Cameron DA. Pretreatment serum anti-mullerian hormone predicts long-term ovarian function and bone mass after chemotherapy for early breast cancer. J Clin Endocrinol Metab. 2011;96(5):1336-43.

17. Lutchman Singh K, Muttukrishna S, Stein RC, McGarrigle HH, Patel A, Parikh $\mathrm{B}$, et al. Predictors of ovarian reserve in young women with breast cancer. Br J Cancer. 2007;96(12):1808-16.

18. Strowitzki T, Capp E, von Eye $\mathrm{CH}$. The degree of cycle irregularity correlates with the grade of endocrine and metabolic disorders in PCOS patients. Eur J Obstet Gynecol Reprod Biol. 2010;149(2):178-81.

19. Petrek JA, Naughton MJ, Case LD, Paskett ED, Naftalis EZ, Singletary SE, et al. Incidence, time course, and determinants of menstrual bleeding after breast cancer treatment: a prospective study. J Clin Oncol. 2006;24(7):1045-51.

20. Tiong $\mathrm{V}$, Rozita AM, Taib NA, Yip $\mathrm{CH}, \mathrm{Ng} \mathrm{CH}$. Incidence of chemotherapyinduced ovarian failure in premenopausal women undergoing chemotherapy for breast cancer. World J Surg. 2014;38(9):2288-96.

21. Jung M, Shin HJ, Rha SY, Jeung HC, Hong S, Moon YW, et al. The clinical outcome of chemotherapy-induced amenorrhea in premenopausal young patients with breast cancer with long-term follow-up. Ann Surg Oncol. 2010;17(12):3259-68.

22. Anders C, Marcom PK, Peterson B, Gu L, Unruhe S, Welch R, et al. A pilot study of predictive markers of chemotherapy-related amenorrhea among premenopausal women with early stage breast cancer. Cancer Invest. 2008;26(3):286-95.

23. Long WQ, Ranchin V, Pautier P, Belville C, Denizot P, Cailla H, et al. Detection of minimal levels of serum anti-Mullerian hormone during follow-up of patients with ovarian granulosa cell tumor by means of a highly sensitive enzymelinked immunosorbent assay. J Clin Endocrinol Metab. 2000;85(2):540-4.

24. Broekmans FJ, de Ziegler D, Howles CM, Gougeon A, Trew G, Olivennes F. The antral follicle count: practical recommendations for better standardization. Fertil Steril. 2010:94(3):1044-51.

Submit your next manuscript to BioMed Central and we will help you at every step:

- We accept pre-submission inquiries

- Our selector tool helps you to find the most relevant journal

- We provide round the clock customer support

- Convenient online submission

- Thorough peer review

- Inclusion in PubMed and all major indexing services

- Maximum visibility for your research

Submit your manuscript at www.biomedcentral.com/submit 